\title{
Preservation of Endothelium-Dependent Vascular Relaxation in Cholesterol-Fed Mice by the Chronic Administration of Prazosin or Pravastatin
}

\author{
Katsuo Kamata, Satoshi Kojima, Makoto Sugiura and Yutaka Kasuya \\ Department of Physiology and Morphology, Institute of Medicinal Chemistry, Hoshi University, Shinagawa-ku, Tokyo 142, Japan \\ Received September 20, 1995 Accepted November 10, 1995
}

\begin{abstract}
The relaxation of aortic rings in response to acetylcholine (ACh) was significantly decreased in cholesterol-fed mice. The attenuated relaxation in cholesterol-fed mice was preserved by the chronic administration of prazosin $(20 \mathrm{mg} / \mathrm{kg} /$ day $)$ or pravastatin $(12.5 \mathrm{mg} / \mathrm{kg} /$ day $)$. Serum low-density lipoprotein (LDL) levels were significantly increased in mice given cholesterol. The increased serum LDL levels in cholesterol-fed mice were returned to normal by the chronic administration of prazosin and pravastatin. A prior incubation of aortic rings with lysophosphatidylcholine (LPC) significantly attenuated ACh- and A23187-induced endothelium-dependent relaxation. The inhibitory effects of LPC on endothelium-dependent relaxation were not affected by indomethacin or superoxide dismutase. The sodium nitroprusside-induced relaxation of aortic rings was not changed by LPC. The inhibitory effects on ACh-induced relaxation by $N^{G}$-monomethyl-L-arginine were restored by a prior exposure to L-arginine, whereas the inhibition of endothelium-dependent relaxation by LPC was not affected by L-arginine. These results suggest that cholesterol-fed mice are useful animal models of hypercholesterolemia, and chronic administration of prazosin or pravastatin can preserve endothelium-dependent relaxation by lowering serum LDL in these animals. It is further suggested that LPC derived from oxidized LDL may be involved in the reduced endotheliumdependent relaxation in hyperlipidemia.
\end{abstract}

Keywords: Low-density lipoprotein (LDL), Endothelium, Pravastatin, Prazosin, Lysophosphatidylcholine (LPC)

Impaired endothelium-dependent relaxations in atherosclerosis have been found in the rabbit aorta $(1-3)$, monkey iliac artery (4), pig coronary artery $(5,6)$, as well as the human coronary artery in vitro $(2,7)$ and in vivo (8). In contrast, there is little information concerning the endothelium-dependent relaxation response to acetylcholine (ACh) in cholesterol-fed mice. The impairment of endothelium-dependent relaxation is thought to play an important role in the pathogenesis of coronary spasm. Oxidative modification of low-density lipoprotein (LDL) cholesterol by the endothelium is thought to be an important step in the initiation of atherosclerosis $(9-11)$. Oxidized LDL cholesterol impairs endothelium-dependent relaxation in isolated arteries $(12,13)$. This inhibitory effect, which is not shared with native LDL, is mediated by lysophosphatidylcholine (LPC) $(12,14-17)$.

Cholesterol is synthesized from acetyl-CoA via a series of over twenty enzymatic reactions. The major rate-limiting step in this pathway is regulated by the activity of the enzyme 3-hydroxy-3-methylglutaryl-coenzyme A reductase (HMG-CoA reductase), which catalyzes the conversion of HMG-CoA to mevalonic acid (18). Pravastatin and prazosin are inhibitors of HMG-CoA reductase $(19-25)$.

The purpose of the present study was to define the relationship between serum LDL levels and endothelial dysfunction in cholesterol-fed mice. We further studied the effects of cholesterol-lowering drugs on the endothelium-dependent relaxation of aortic rings in response to $\mathrm{ACh}$ or the $\mathrm{Ca}$ ionophore $\mathrm{A} 23187$ in cholesterol-fed mice.

\section{MATERIALS AND METHODS}

\section{Animals}

Male ICR (Institute of Cancer Research) mice, aged 5 weeks and weighing $27.8 \pm 1.4 \mathrm{~g}$, were housed under constant climatic conditions (temperature of $21^{\circ} \mathrm{C}-22^{\circ} \mathrm{C}$, 
relative air humidity of $50 \pm 5 \%$ ). The mice were purchased from Tokyo Laboratory Animals Co., Ltd. (Tokyo). The diets and water were given ad libitum to all animals. This study was conducted in accordance with the Guide for the Care and Use of Laboratory Animals adopted by the Committee on the Care and Use of Laboratory Animals of Hoshi University, which is accredited by the Ministry of Education, Science, Sports and Culture, Japan.

\section{Experimental design}

Mice were randomly divided into two groups. Control mice received a standard mouse diet, and cholesterol-fed mice received a diet supplemented with $2 \%$ cholesterol (wt/wt) and $0.5 \%$ cholic acid (wt/wt). This feeding program was adhered to for 10 weeks. The cholesterol diet markedly increased the serum levels of total cholesterol from $119.4 \pm 8.1$ to $215.5 \pm 13.8 \mathrm{mg} / \mathrm{dl}(\mathrm{P}<0.01, \mathrm{n}=14)$. Cholesterol-fed mice received saline, pravastatin $(12.5$ $\mathrm{mg} / \mathrm{kg}$, p.o., daily for 10 weeks) or prazosin $(20 \mathrm{mg} / \mathrm{kg}$, p.o., daily for 10 weeks).

\section{Measurement of isometric force}

After 10 weeks of dietary intervention, the control and cholesterol-fed mice were anesthetized with ether, a midline incision was made, and blood was obtained from the abdominal aorta. The blood was centrifuged at $3000 \mathrm{rpm}$ for $10 \mathrm{~min}$ at $4{ }^{\circ} \mathrm{C}$, and the plasma was isolated and stored at $-80^{\circ} \mathrm{C}$. After the bleeding, the aorta was rapidly dissected and placed in ice-cold modified Krebs-Henseleit solution (KHS, composition: $118 \mathrm{mM} \mathrm{NaCl}, 4.7 \mathrm{mM} \mathrm{KCl}$, $25.0 \mathrm{mM} \mathrm{NaHCO}, 1.8 \mathrm{mM} \mathrm{CaCl}, 1.2 \mathrm{mM} \mathrm{NaH} \mathrm{PO}_{4}$, $1.2 \mathrm{mM} \mathrm{MgSO}_{4}, 11.0 \mathrm{mM}$ dextrose). Each aorta was separated from the surrounding connective tissue and cut into rings (3-mm-long). Special care was taken not to damage the endothelium. The rings were then suspended in organ bath chambers, between a clip and a force-displacement transducer (TB-611T; Nihon Kohden, Tokyo) by means of two stainless steel wires inserted into the lumen, under a resting tension of $1.5 \mathrm{~g}$ (preliminary determined to be optimum), to measure isometric force. The organ chamber was filled with $10 \mathrm{ml}$ of KHS at $37^{\circ} \mathrm{C}$ and gassed with $95 \% \mathrm{O}_{2}-5 \% \mathrm{CO}_{2}$. Following a $1-\mathrm{hr}$ equilibration period, prostaglandin $\mathrm{F}_{2 \alpha}\left(\mathrm{PGF}_{2 \alpha}\right)$ was added to the organ bath at a concentration high enough $\left(10^{-6}-3 \times 10^{-6} \mathrm{M}\right)$ to induce ring contraction. After the $\mathrm{PGF}_{2 \alpha}$-induced contraction reached a plateau, $10^{-5} \mathrm{M}$ $\mathrm{ACh}$ was added to the organ bath to confirm the integrity of the endothelium. The mice aortic rings were completely relaxed at this concentration of ACh. The removal of endothelial cells by rubbing was confirmed by the fact that tonic contraction of the aortic ring by $\mathrm{PGF}_{2 \alpha}$ was not affected by $\mathrm{ACh}$. The effects of drugs were then tested.
The tissue was allowed to relax and equilibrate for $40 \mathrm{~min}$ before the next application of drugs. Because the maximal contraction of aortic rings in response to $\mathrm{PGF}_{2 \alpha}$ was enhanced significantly in cholesterol-fed mice, for the relaxation studies aortic rings were precontracted with an equieffective concentration of $10^{-6}$ to $3 \times 10^{-6} \mathrm{M} \mathrm{PGF}_{2 \alpha}$ so that the rings would register a development of tension of approximately $860 \mathrm{mg}$ from age-matched control and cholesterol-fed mice. To obtain the tension of approximately $860 \mathrm{mg}, \mathrm{PGF}_{2 \alpha}\left(10^{-6}-3 \times 10^{-6} \mathrm{M}\right)$ was added to the bath cumulatively. When the $\mathrm{PGF}_{2 \alpha}$-induced contraction reached a plateau, relaxant agents were added in a cumulative manner. To examine $\mathrm{ACh}$-induced relaxation in the presence of $N^{G}$-monomethyl-L-arginine (L-NMMA) or LPC, the aortic rings were exposed to L-NMMA or LPC for $30 \mathrm{~min}$, and then ACh was cumulatively added to the bath. The relaxation in response to each agent was expressed as the percentage of decreased tension of contractile force induced by $10^{6}$ to $3 \times 10^{-6} \mathrm{M} \mathrm{PGF}_{2 \alpha}$.

\section{Measurement of serum cholesterol}

Serum cholesterol levels were determined by a commercially available enzyme kit (Wako Pure Chemical Industries, Osaka).

\section{Drugs}

LPC, L-NMMA, L-arginine, indomethacin, superoxide dismutase (SOD), calcium ionophore A23187, sodium nitroprusside (SNP), dimethylsulfoxide (DMSO) and prazosin were all purchased from Sigma Chemical Co. (St. Louis, MO, USA). ACh was purchased from Daiichi Pharmaceutical Co., Ltd. (Tokyo). Pravastatin was purchased from Sankyo Pharmaceutical Co., Ltd. (Tokyo). $\mathrm{PGF}_{2 \alpha}$ was purchased from Ono Pharmaceutical Co., Ltd. (Osaka). LPC was dissolved in ethanol and stored at $-20^{\circ} \mathrm{C}$. On the day of use, the ethanol was evaporated and replaced with $0.9 \%$ saline. A23187 was dissolved in DMSO. The final concentration of DMSO in the organ bath was $0.1 \%$, which had no effect on contraction or relaxation. $\mathrm{PGF}_{2 \alpha}$, L-NMMA, L-arginine indomethacin and SOD were dissolved in $0.9 \%$ saline immediately before each experiment. Concentrations are expressed as the final concentration of each drug in the organ bath.

\section{Statistics}

Data are expressed as means \pm S.E. Statistical differences were measured by Student's $t$-test for unpaired observations, following one-way analysis of variance. 


\section{RESULTS}

\section{Relaxation in response to $A C h$ or $S N P$ in the aortas from control and cholesterol-fed mice}

The body weight of the mice in the two groups was similar at the start of the experiment (control, 27.7 \pm 2.1 $\mathrm{g}$; cholesterol-fed group, $27.9 \pm 2.3 \mathrm{~g}$ ), and the rate of weight gain was similar in these groups. The serum cholesterol levels were also similar in the two groups at the start of the experiments (control, $117.1 \pm 7.8 \mathrm{mg} / \mathrm{dl}$; cholesterol-fed group, $119.4 \pm 8.1 \mathrm{mg} / \mathrm{dl}$ ). The control group did not show any change in serum cholesterol over 10 weeks, but the cholesterol-fed group had significantly elevated serum cholesterol levels (control, 125.9 \pm 3.4

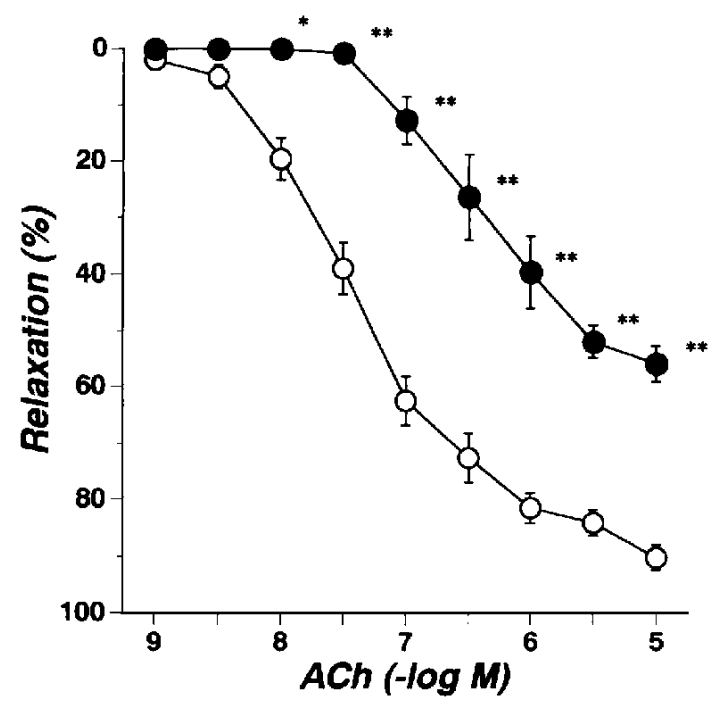

Fig. 1. Concentration-response curves of acetylcholine (ACh)-induced relaxation of aortic rings obtained from age-matched control and cholesterol-fed mice. The aortic rings were contracted with $10^{-6}$ to $3 \times 10^{-6} \mathrm{M} \mathrm{PGF}_{2 \alpha}$. Open circles: control mice; solid circles: cholesterol-fed mice. The ordinate scale shows the relaxation of aortic rings as a percentage of the contraction induced by $10^{-6}$ to $3 \times 10^{-6} \mathrm{M} \mathrm{PGF}_{2 a}$. Each data point on the graph represents the mean \pm S.E. of six experiments; the vertical lines indicate the S.E. and are only included when they exceeded the dimensions of the symbols used. ${ }^{*} \mathrm{P}<0.05,{ }^{* *} \mathrm{P}<0.01$. $\mathrm{mg} / \mathrm{dl}$; cholesterol-fed group, $\quad 215.5 \pm 13.8 \mathrm{mg} / \mathrm{dl}$; $\mathrm{P}<0.01, \mathrm{n}=30$ ).

In aortic rings from the control mice, ACh $\left(10^{-9}-\right.$ $10^{-5} \mathrm{M}$ ) caused concentration-dependent relaxation, reaching a maximum at $10^{-5} \mathrm{M}$ (Fig. 1). The relaxation caused by $\mathrm{ACh}$ was significantly decreased in rings from mice that received the cholesterol-rich diet (Fig. 1). After chronic administration with pravastatin $(12.5 \mathrm{mg} / \mathrm{kg}$, p.o., daily for 10 weeks) or prazosin $(20 \mathrm{mg} / \mathrm{kg}$, p.o., daily for 10 weeks), aortic rings from the cholesterol-fed mice relaxed in a normal response to ACh (Fig. 2).

Treating the control mice with pravastatin or prazosin had no significant effect on relaxation caused by $\mathrm{ACh}$ (Table 1). The relaxation caused by SNP $\left(10^{-9}-10^{-5} \mathrm{M}\right)$

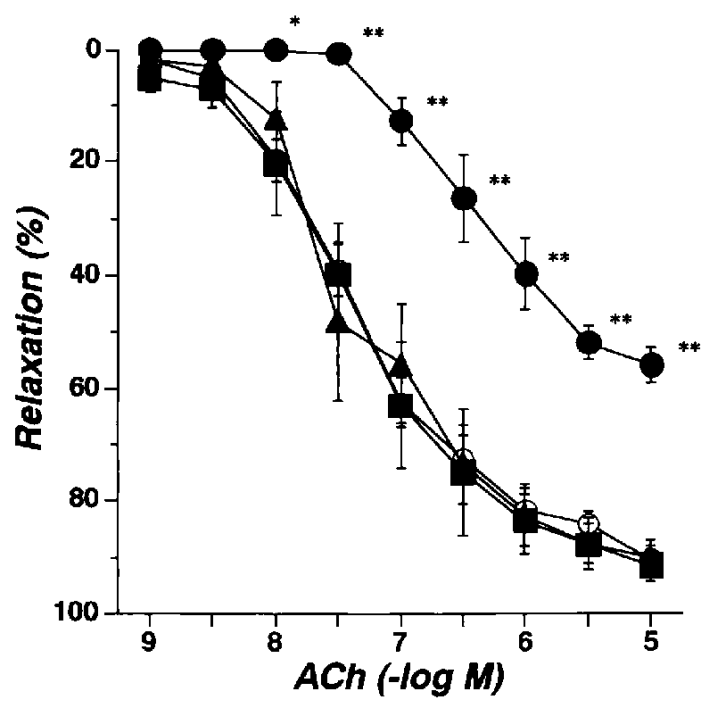

Fig. 2. Concentration-response curves of acetylcholine (ACh)-induced relaxation of aortic rings obtained from age-matched control, cholesterol-fed mice and cholesterol-fed mice that had been given pravastatin or prazosin. The aortic rings were contracted with $10^{-6}$ to $3 \times 10^{-6} \mathrm{M} \mathrm{PGF}_{2 x}$. Open circles: control mice; solid circles: cholesterol-fed mice; solid squares: cholesterol-fed, pravastatin-treated mice; solid triangles: cholesterol-fed, prazosin-treated mice. The ordinate scale shows the relaxation of aortic rings as a percentage of the contraction induced by $10^{-6}$ to $3 \times 10^{-6} \mathrm{M} \mathrm{PGF}{ }_{2 \alpha}$. Each data point on the graph represents the mean \pm S.E. of six experiments; the vertical lines indicate the S.E. and are only included when they exceeded the dimensions of the symbols used. ${ }^{*} \mathrm{P}<0.05,{ }^{* *} \mathrm{P}<0.01$.

Table 1. Relaxation responses of age-matched control mouse aorta to acetylcholine (ACh) or sodium nitroprusside (SNP) following chronic administration of pravastatin or prazocin

\begin{tabular}{|c|c|c|c|c|c|}
\hline & & \multicolumn{2}{|l|}{$\mathrm{ACh}$} & \multicolumn{2}{|l|}{ SNP } \\
\hline & & maximum relaxation, $\%$ & $\mathrm{pD}_{2}, \mathrm{M}$ & maximum relaxation, $\%$ & $\mathrm{pD}_{2}, \mathrm{M}$ \\
\hline Control & $(\mathrm{n}=6)$ & $91.1 \pm 3.9$ & $1.0 \pm 0.1 \times 10^{-7}$ & $99.5 \pm 0.3$ & $3.1 \pm 0.1 \times 10^{8}$ \\
\hline Control + Pravastatin & $(n=6)$ & $90.6 \pm 2.6$ & $1.1 \pm 0.2 \times 10^{-7}$ & $99.7 \pm 1.6$ & $2.9 \pm 0.3 \times 10^{-8}$ \\
\hline Control + Prazocin & $(n=6)$ & $93.6 \pm 5.2$ & $1.3 \pm 0.1 \times 10^{-7}$ & $96.8 \pm 1.2$ & $3.0 \pm 0.3 \times 10^{-8}$ \\
\hline
\end{tabular}

Results are means \pm S.E. 




Fig. 3. Concentration-response curves of the sodium nitroprusside (SNP)-induced relaxation of aortic rings obtained from cholesterol-fed mice and cholesterol-fed mice that had been given pravastatin or prazosin. The aortic rings were precontracted with $10^{-6}$ to $3 \times$ $10^{-6} \mathrm{M} \mathrm{PGF}_{2 \varkappa}$. Solid circles: cholesterol-fed mice; solid squares: cholesterol-fed, pravastatin-treated mice; solid triangles: cholesterol-fed, prazosin-treated mice. The ordinate scale shows the relaxation of aortic rings as a percentage of the contraction induced by $10^{-6}$ to $3 \times 10^{-6} \mathrm{M} \mathrm{PGF}_{2 \alpha}$. Each data point on the graph represents the mean $\pm S$.E. of six experiments; the vertical lines indicate the S.E. and are only included when they exceeded the dimensions of the symbols used.



Fig. 4. Effects of prazosin or pravastatin on cholesterol levels in cholesterol-fed mice. Cholesterol-fed mice received prazosin $(20$ $\mathrm{mg} / \mathrm{kg}$, p.o., daily for 10 weeks) or pravastatin $(12.5 \mathrm{mg} / \mathrm{kg}, \mathrm{p} .0$., daily for 10 weeks). A: control mice; $B$ : cholesterol-fed mice; C: cholesterol-fed, prazosin-treated mice; D: cholesterol-fed, pravastatin-treated mice. Each column represents the mean \pm S.E. of six experiments; the vertical lines indicate the S.E. ${ }^{* *} \mathrm{P}<0.01$, vs control (A); ${ }^{4} \mathrm{P}<0.05$, vs cholesterol-fed group (B). was not significantly different in aortic rings from the different groups (Fig. 3). Treating control mice with pravastatin or prazosin had no significant effect on the relaxation caused by SNP (Table 1).

\section{Effects of chronic administration of pravastatin or prazosin on serum cholesterol level}

In mice that received the cholesterol-rich diet for 10 weeks, serum total cholesterol and LDL levels were significantly increased (Fig. 4).

Chronic administration of pravastatin $(12.5 \mathrm{mg} / \mathrm{kg}$, p.o., daily for 10 weeks) or prazosin $(20 \mathrm{mg} / \mathrm{kg}$, p.o., daily for 10 weeks) significantly reduced the total cholesterol and LDL levels in cholesterol-fed mice as shown in Fig. 4.

Effects of LPC and L-NMMA on ACh-, A23187- and $S N P$-induced relaxations

LPC and L-NMMA did not affect the resting tonus of mouse aortic rings. After exposure to LPC $(5 \mu \mathrm{g} / \mathrm{ml})$ for $30 \mathrm{~min}$, ACh-induced relaxation was significantly decreased in control mice (Fig. 5). The decreased AChinduced relaxation was not changed by co-incubation with $10^{-2} \mathrm{M}$ L-arginine (Fig. 5). The ACh-induced concentration-dependent relaxation of control mouse aortic

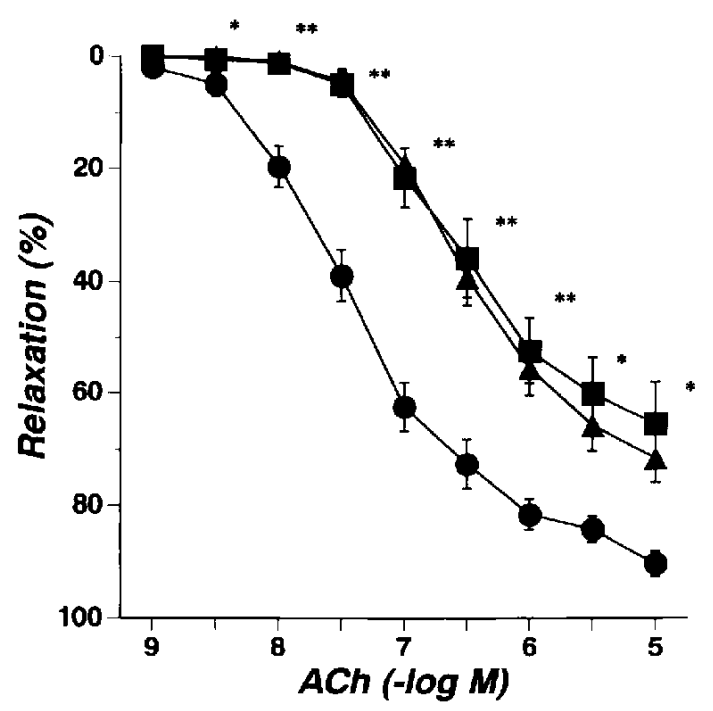

Fig. 5. Effects of lysophosphatidylcholine (LPC) or LPC plus Larginine on the acetylcholine $(\mathrm{ACh})$-induced dose-dependent relaxation of aortic rings from normal mice. The aortic rings were contracted with $10^{-6}$ to $3 \times 10^{-6} \mathrm{M} \mathrm{PGF}_{2 n}$. Solid circles: control, solid squares: LPC-treated aortas, solid triangles: LPC with L-argininetreated aortas. The ordinate scale shows the relaxation of aortic rings as a percentage of the contraction induced by $10^{-6}$ to $3 \times$ $10^{-6} \mathrm{M} \mathrm{PGF}_{2 a}$. Each data point on the graph represents the mean \pm S.E. of six experiments; the vertical lines indicate the S.E. and are only included when they exceeded the dimensions of the symbols used. ${ }^{*} \mathbf{P}<0.05,{ }^{* *} \mathbf{P}<0.01$. 




Fig. 6. Effects of $N^{G}$-monomethyl-L-arginine (L-NMMA) or LNMMA plus L-arginine on the acetylcholine ( $\mathrm{ACh}$ )-induced dosedependent relaxation of aortic rings from normal mice. The aortic rings were first contracted with $10^{-6}$ to $3 \times 10^{-6} \mathrm{M} \mathrm{PGF}_{2,}$. Solid circles: control, solid squares: L-NMMA-treated aortas, solid triangles: L-NMMA and L-arginine-treated aortas. The ordinate scale shows the relaxation of aortic rings as a percentage of the contraction induced by $10^{-6}$ to $3 \times 10^{-6} \mathrm{M} \mathrm{PGF}_{2_{a}}$. Each data point on the graph represents the mean \pm S.E. of six experiments; the vertical lines indicate the S.E. and are only included when they exceeded the dimensions of the symbols used. ${ }^{*} \mathrm{P}<0.05,{ }^{* *} \mathrm{P}<0.01$.

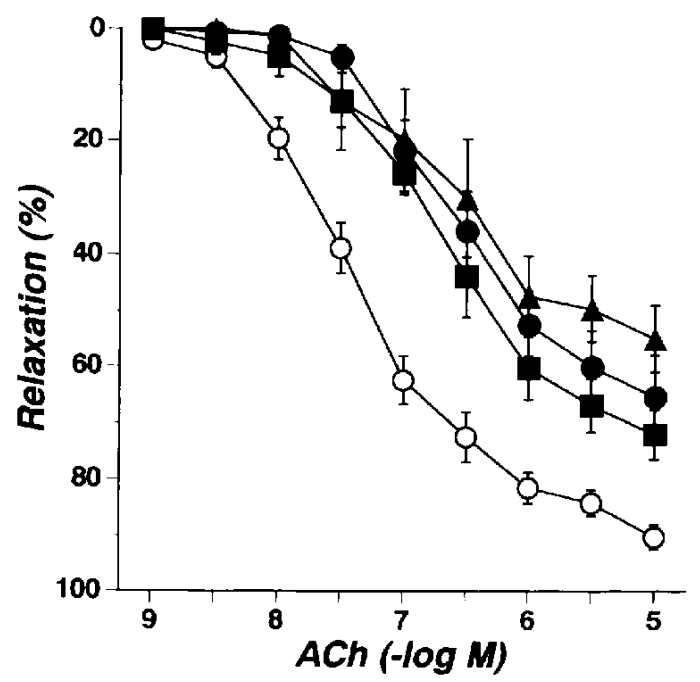

Fig. 7. Effects of lysophosphatidylcholine (LPC), LPC plus indomethacin or LPC plus superoxide dismutase (SOD) on the acetylcholine (ACh)-induced dose-dependent relaxation of aortic rings from normal mice. The aortic rings were initially contracted with $10^{-6}$ to $3 \times 10^{-6} \mathrm{M} \mathrm{PGF}_{2 \alpha}$. Open circles: control, solid circles: LPCtreated aortas, solid squares: LPC and indomethacin-treated aortas, solid triangles: LPC and SOD-treated aortas. The ordinate scale shows the relaxation of aortic rings as a percentage of the contraction induced by $10^{6}$ to $3 \times 10^{-6} \mathrm{M} \mathrm{PGF}_{2,8}$. Each data point on the graph represents the mean \pm S.E. of six experiments; the vertical lines indicate the S.E. and are only included when they exceeded the dimensions of the symbols used.

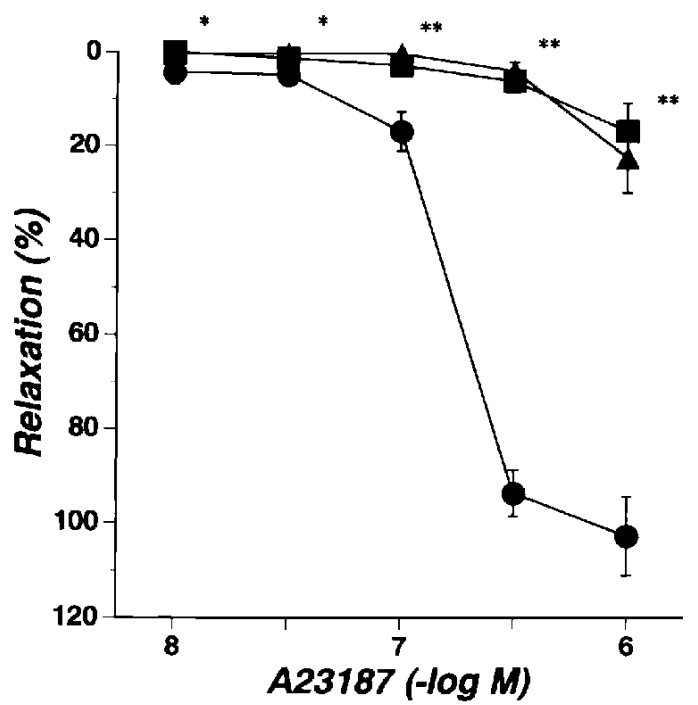

Fig. 8. Effects of $N^{G}$-monomethyl-L-arginine (L-NMMA) and lysophosphatidylcholine (LPC) on the A23187-induced dose-dependent relaxation of aortic rings from normal mice. The aortic strips were initially contracted with $10^{-6}$ to $3 \times 10^{-6} \mathrm{M} \mathrm{PGF}_{2 \alpha}$. Solid circles: control, solid squares: L-NMMA-treated aortas, solid triangles: LPC-treated aortas. The ordinate scale shows the relaxation of aortic rings as a percentage of the contraction induced by $10^{-6}$ to $3 \times$ $10^{-6} \mathrm{M} \mathrm{PGF}$ Prr . Each data point on the graph represents the mean \pm S.E. of six experiments; the vertical lines indicate the S.E. and are only included when they exceeded the dimensions of the symbols used. ${ }^{*} \mathrm{P}<0.05,{ }^{* *} \mathrm{P}<0.01$.

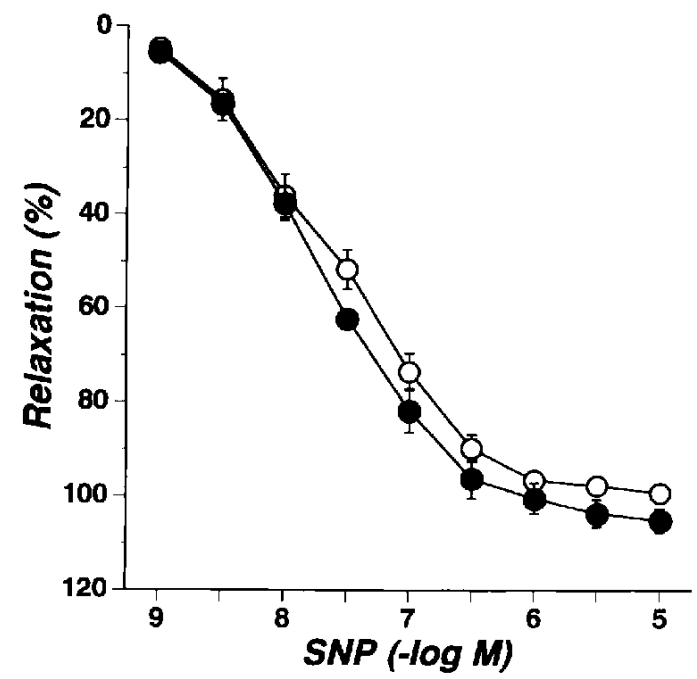

Fig. 9. Effects of lysophosphatidylcholine (LPC) on the sodium nitroprusside (SNP)-induced dose-dependent relaxation of aortic rings from normal mice. The aortic rings were initially contracted with $10^{-6}$ to $3 \times 10^{-6} \mathrm{M} \mathrm{PGF}_{2, \mathrm{r}}$. Open circles: control, solid circles: LPC-treated aortas. The ordinate scale shows the relaxation of aortic rings as a percentage of the contraction induced by $10^{-6}$ to $3 \times$ $10^{-6} \mathrm{M} \mathrm{PGF}_{2, x}$. Each data point on the graph represents the mean \pm S.E. of six experiments; the vertical lines indicate the S.E. and are only included when they exceeded the dimensions of the symbols used. 
rings was significantly decreased by a prior incubation with $10^{-4} \mathrm{M}$ L-NMMA for $30 \mathrm{~min}$ (Fig. 6). However, the decreased ACh-induced relaxation was restored by a combined incubation with $10^{-4} \mathrm{M}$ L-NMMA and $10^{-2} \mathrm{M}$ L-arginine (Fig. 6). The decreased $\mathrm{ACh}$-induced relaxation of aortic rings by LPC was not affected by $10{ }^{5} \mathrm{M}$ indomethacin and 200 units/ml SOD (Fig. 7).

A prior incubation with L-NMMA $\left(10^{-4} \mathrm{M}\right)$ or LPC (5 $\mu \mathrm{g} / \mathrm{ml})$ markedly inhibited the A23187-induced relaxation of control mice aortic rings (Fig. 8).

A prior incubation with LPC $(5 \mu \mathrm{g} / \mathrm{ml})$ had no significant effect on SNP-induced relaxation (Fig. 9).

\section{DISCUSSION}

In the present study, we found that the chronic administration of pravastatin or prazosin preserves the endothelium-dependent relaxation of aorta isolated from cholesterol-fed mice and significantly reduces the total cholesterol and as well as LDL cholesterol levels in cholesterol-fed mice. A prior incubation with LPC significantly attenuated the ACh-and the A23187-induced endothelium-dependent relaxation of aortic rings. The inhibitory effects on $\mathrm{ACh}$-induced relaxation were restored by a prior exposure to L-arginine, whereas the inhibition of endothelium-dependent relaxation by LPC was not affected by $\mathrm{L}$-arginine.

A reduction in the release of endothelium-derived relaxing factor from the vascular endothelium or a decrease in endothelium-dependent relaxation has been demonstrated in vascular tissue obtained from cholesterol-fed rabbits and in human atherosclerotic coronary arteries $(1-7)$. Consistent with these findings, we found that $\mathrm{ACh}$-induced endothelium-dependent relaxation was significantly attenuated in cholesterol-fed mice. Since the endothelium-independent relaxation of mouse aortic rings by SNP was not changed in cholesterol-fed mice, the activity of guanylate cyclase in the smooth muscle of the aorta was not altered. These results suggest that the mouse is also useful as an animal model of hypercholesterolemia.

The inhibitory effects of pravastatin on HMG CoA reductase are well-documented $(19,20)$. Long-term exposure to pravastatin reduces LDL cholesterol concentrations (26). Lowering cholesterol with lovastatin significantly improves endothelium-mediated responses in the coronary arteries of patients with atherosclerosis (27). Such improvement in the local regulation of coronary arterial tone could relieve ischemic symptoms and signal the stabilization of atherosclerotic plaques. It has been reported that $\alpha$-blockers lower serum cholesterol levels by inhibiting the activity of HMG-CoA in the liver $(21-25)$. Although HMG CoA reductase inhibitors (pravastatin or prazosin) have a beneficial effect on lipids, there are few reports concerning the positive effects of these agents on endothelial dysfunction in cholesterolemia after the chronic administration of these agents in animals. In cholesterol-fed mice, serum total cholesterol and LDL cholesterol levels were significantly increased, and the increased cholesterol levels were normalized by the chronic administration of pravastatin or prazosin. The endothelium-dependent relaxation of aortic rings in response to $\mathrm{ACh}$ was significantly attenuated in cholesterol-fed mice, and the impaired endothelium-dependent relaxation was restored by chronic administration of pravastatin or prazosin. These results suggest that endothelial dysfunction in cholesterol-fed mice is due to the increased LDL, and that the endothelium-dependent relaxation may be preserved by the chronic administration of pravastatin or prazosin, at least in part, through lowering the serum LDL levels.

An endothelium dysfunction is intimately involved in the pathogenesis of atherosclerosis $(28-30)$. The oxidative modification of LDL cholesterol by the endothelium is thought to be an important step in the alteration of various endothelial functions $(12,13)$ and the initiation of atherosclerosis (31). LPC, which is transferred from oxidized LDL to the endothelial surface membrane, is involved in the mechanisms of the endothelial functional alterations caused by oxidized LDL $(12,15-17)$. In the present study, we confirmed that the endothelium-dependent relaxation of aortic rings in response to $\mathrm{ACh}$ or A23187 were significantly attenuated by LPC. Since A23187-induced relaxation was reduced by LPC, the impairment of endothelium-dependent relaxation by LPC is not muscarinic receptor antagonistic action. L-NMMA, an inhibitor of nitric oxide (NO) synthase, also effectively inhibited the ACh-induced relaxation responses. The inhibitory effect of L-NMMA on ACh-induced relaxation was reversed by co-administration of L-arginine. In contrast to L-NMMA, the inhibition of ACh-induced relaxation by LPC was not reversed by co-administration of Larginine, suggesting that the inhibitory effect of LPC on ACh-induced relaxation is not due to impaired NO synthase activity. We found that the inhibitory effect of LPC on ACh-induced relaxation was not affected by indomethacin or SOD, ruling out the prostanoids or superoxide anions.

LPC in oxidized LDL is transferred and incorporated into the endothelial surface membrane in an apoproteinindependent manner $(12,32,33)$. LPC is a by-product of cholesterol esterification and is formed during oxidation of LDL $(14,34)$. In cholesterol-fed animals, LPC accumulates in the vessel wall $(35,36)$, and LPC has been found in atherosclerotic vascular lesions in human (36). The levels of LPC in human atherosclerotic lesions are 
similar to those used in the present experiments, although the intracellular concentration is not precisely known. Considerable evidence suggests that the activation of protein kinase $\mathrm{C}$ by phorbol esters inhibits the endotheliumdependent vasodilation induced by agonists $(37-42)$. Therefore, the release of LPC from oxidized LDL must play an important role in endothelial function. If so, the following sequence of events occured in cholesterol-fed mice: serum LDL levels are increased in cholesterol-fed mice; increased LDL is oxidized on the endothelium; LPC is transferred from oxidized LDL; LPC may activate protein kinase $C$; activated protein kinase $C$ may inhibit the endothelium-dependent vasodilation induced by agonists, thereby resulting in endothelial dysfunction in cholesterol-fed mice. In the present study, the chronic administration of pravastatin or prazosin significantly lowered serum LDL levels. This cholesterol-lowering effect of pravastatin or prazosin may improve the endothelium-dependent relaxation.

LPC may not affect soluble guanylate cyclase activity, because SNP-induced relaxation was not affected by LPC.

In conclusion, we demonstrated that the endotheliumdependent relaxation of aortic strips obtained from cholesterol-fed mice is significantly attenuated. Chronic administration of pravastatin or prazosin reduced serum LDL levels and restored endothelium-dependent relaxation.

\section{Acknowledgments}

This study was supported in part by Grants-in-Aid No. 05671908 and 06672282 from the Ministry of Education, Science, Sports and Culture, Japan and the Shimabara Memorial Foundation, Japan

\section{REFERENCES}

1 Verbeuren $\mathrm{TJ}$, Jordens $\mathrm{FH}$, Zonnekeyn $\mathrm{LL}$, Vanhove $\mathrm{CE}$, Coene $\mathrm{MC}$ and Herman AG: Effect of hypercholesterolemia on vascular reactivity in the rabbit. I. Endothelium-dependent and endothelium-independent contractions and relaxations in isolated arteries of control and hypercholesterolemic rabbits. Circ Res 58, 552-564 (1986)

2 Bossaller C, Habib GB, Yamamoto H, Williams C, Wells W and Henry PD: Impaired muscarinic endothelium-dependent relaxation and cyclic guanosine $3^{\prime}, 5^{\prime}$-monophosphate formation in the atherosclerotic human coronary artery and rabbit aorta. $\mathrm{J}$ Clin Invest 79, 170-174 (1987)

3 Jayakody L, Senarine M, Thomoson A and Kappagoda T: Endothelium-dependent relaxation in experimental atherosclerosis in the rabbit. Circ Res 60, 251-264 (1987)

4 Freiman RC, Mitchell GG, Heistad DD, Armstrong Ml and Harrison DG: Atherosclerosis impairs endothelium-dependent vascular relaxation to acetylcholine and thrombin in primates. Circ Res 58, $783-789$ (1986)

5 Yamamoto $Y$, Tomoike $H$, Egashira $K$ and Nakamura $M$ : Attenuation of endothelium-related relaxation and enhanced responsiveness of vascular smooth muscle to histamine in spastic coronary arterial segments from miniature pigs. Circ Res 61, $772-778$ (1987)

6 Shimokawa $\mathrm{H}$ and Vanhoutte PM: Impaired endotheliumdependent relaxation to aggregating platelets and related vasoactive substances in porcine coronary arteries in hypercholesterolemia and atherosclerosis. Circ Res 64, 900-914 (1989)

7 Forstermann U, Mugge A, Alheid U, Haverich A and Frolich JC: Selective attenuation of endothelium-mediated vasodilation in atherosclerotic human coronary arteries. Circ Res 62, $185-190(1988)$

8 Lunder Pl, Selwyn AP, Shook TI, Wayne RR and Mudge GH: Paradoxical vasoconstriction induced by acetylcholine in atherosclerotic coronary arteries. $N$ Engl J Med 315, $1046-1050$ (1986)

9 Quinn MT, Parthasarathy S, Fong LG and Steinberg D: Oxidatively modified low density lipoproteins: a potential role in recruitment and retention of monocyte/macrophages during atherogenesis. Proc Natl Acad Sci USA 84, 2995-2998 (1987)

10 Berliner JA, Territo MC, Sevanian A, Ramins S, Kim JAi, Bamshad B, Esterson $M$ and Fogelman AM: Minimally modified low density lipoprotein stimulates monocyte endothelial interaction. J Clin Invest 85, 1260-1267 (1990)

11 Steinbrecher UP, Parthasarrathy S, Leake DS, Witztum JL and Steinberg D: Modification of low density lipoprotein by endothelial cells involves lipid peroxidation and degradation of low density lipoprotein phospholipids. Proc Natl Acad Sci USA 81, 3883 - 3887 (1984)

12 Kugiyama K, Kerns SA, Morrisett JD, Roberts R and Henry PD: Impairment of endothelium-dependent arterial relaxation by lysolecithin in modified low-density lipoproteins. Nature 344, $160-162(1990)$

13 Witztum $\mathrm{JL}$ and Steinberg $\mathrm{D}$; Role of oxidized low density lipoprotein in atherosclerosis. J Clin Invest 88, 1785-1792 (1991)

14 Yokoyama M, Hirata K, Miyake R, Akita H, Ishikawa Y and Fukuzaki H: Lysophosphatidylcholine: essential role in the inhibition of endothelium-dependent vasorelaxation by oxidized low-density lipoprotein. Biochem Biophys Res Commun 168, $301-308$ (1990)

15 Kugiyama K, Ohgushi M, Sugiyama S, Murohara T, Fukunaga $\mathrm{K}$, Miyamoto $\mathrm{E}$ and Yasue $\mathrm{H}$ : Lysophosphatidylcholine inhibits surface receptor-mediated intracellular signals in endothelial cells by a pathway involving protein kinase $\mathrm{C}$ activation. Circ Res 71, 1422- 1428 (1992)

16 Sugiyama S, Kugiyama K, Ohgushi M, Fujimoto K and Yasue $\mathrm{H}$ : Lysophosphatidylcholine in oxidized low-density lipoprotein increases endothelial susceptibility to polymorphonuclear leukocyte-induced endothelial dysfunction in porcine coronary arteries. Role of protein kinase C. Circ Res 74, $565-575$ (1994)

17 Flavahan NA: Lysophosphatidylcholine modifies G proteindependent signaling in porcine endothelial cells. Am J Physiol 264, H722- H727 (1993)

18 Lee T-J: Synthesis, SARs and therapeutic potential of HMGCoA redcutase inhibitors. Trends Pharmacol Sci 8, 442-446 (1987)

19 Saxenhofer H, Weidmann P, Riesen WF, Beretta-Piccoli C, Fragiacomo C, Wunderlin R and Noseda G: Therapeutic efficacy of the HMG-CoA-reductase inhibitor pravastatin in hyper- 
lipoproteinaemaia type II. Eur J Clin Pharmacol 39, 101-105 (1990)

20 Hunninghake DB, Knopp RH, Schonfeld G, Goldberg AC, Brown WV, Schaefer EJ, Margolis S, Dobs AS, Mellies MJ, Insull $\mathrm{W} \mathrm{Jr}$ and Stein EA: Efficacy and safety of pravastatin in patient with primary hypercholesterolemia. I. A dose-response study. Atherosclerosis 85, 81-89 (1990)

21 Krupp MN, Hoover KW and Valentine JJ: Effects of doxazosin and other antihypertensive on serum lipid levels and lipoprotein lipase in the C57BR/cdj mouse. J Cardiovasc Pharmacol 13, Supp 2, S11-S19 (1989)

22 Pool JL: Plasma lipid lowering effects of doxazosin, a new selective alphal, adrenergic inhibitor for systemic hypertension. Am J Cardiol 59, 46G-50G (1987)

23 Frick $\mathrm{MH}$, Cox DA, Himanen $\mathrm{P}$, Himanen $\mathrm{P}$, Huttunen $\mathrm{M}$, Pitkajarvi T, Porsti P, Poyhonen L, Pyykonen M-L, Reinikainen $P$, Saimeia $P$ and Saraste $M$ : Serum lipid changes in $\mathbf{a}$ one-year, multicenter, double-blind comparison of doxazosin and atenolol for mild to moderate essential hypertension. Am J Cardiol 59, 61G-67G (1987)

24 Grimm RH: Thiazide diuretics and selective alpha blockers: comparison of use in antihypertensive therapy, including possible differences in coronary heart disease risk reduction. Am J Med 82, 26-29 (1987)

25 Graham RM: Selective alpha-1-adrenergic blockade, lipids, and coronary heart disease risk: consideration in the treatment of essential hypertension. Am J Med 87, 53S- 56 S (1989)

26 Jacob BG, Richter WO and Schwandt P: Long-term treatment (2 years) with the HMG CoA reductase inhibitors lovastatin or pravastatin in combination with cholestyramine in patient with severe primary hypercholesterolemia. J Cardiovasc Pharmacol 22, 396-400 (1993)

27 Treasure CB, Klein JL, Weintraub WS, Talley JD, Stillabower ME, Kosinski AS, Zhang J, Boccuzzi SJ, Cedarholm JC and Alexander RW: Beneficial effects of cholesterol-lowering therapy on the coronary endothelium in patients with coronary artery disease. N Eng J Med 332, 481 - 487 (1995)

28 Ross R: The pathogenesis of atherosclerosis: an update. N Eng J Med 314, 488-500 (1986)

29 Yasue H, Matsuyama K, Matsuyama K, Okumura K, Morigami $\mathrm{Y}$ and Ogawa $\mathrm{H}$ : Response of angiographically normal human coronary arteries to intracoronary injection of acetylcholine by age and segment: possible role of early coronary atherosclerosis. Circulation 81, $482-490$ (1990)

30 Bossaller C, Habib GB, Yamamoto H, Williams C, Wells S and Henry PD: Impaired muscarinic endothelium-dependent relaxation and cyclic guanosine 5'-monophosphate formation in atherosclerotic human coronary artery and rabbit aorta. J Clin Invest 79, 170-174 (1987)
31 Steinberg UP, Parthasarathy S, Leake DS, Witzum JL and Steinberg D: Modification of low density lipoprotein by endothelial cells involves lipid peroxidation and degradation of low density lipoprotein phospholipids. Proc Natl Acad Sci USA 81, 3883-3887 (1984)

32 Kugiyama K and Henry PD: Transfer of lysophosphatidylcholine from oxidized LDL to endothelial cells impairs endothelium-dependent arterial relaxation. J Am Coll Cardiol 15, 12A, Abstract (1990)

33 Ohgushi M, Kugiyama K, Fukunaga K, Murohara T, Sugiyama $S$ and Miyamoto E: Protein kinase $C$ inhibitors prevent impairment of endothelium-dependent relaxation by oxidatively modified low-density lipoprotein. Arterioscler Thromb 13, 1525 - 1532 (1993)

34 Parthasarathy S, Steimbrecher UP, Barnett J, Witztum JL and Steinberg D: Essential role of phospholipase $\mathrm{A}_{2}$ activity in endothelial cell-induced modification of low density lipoprotein. Proc Natl Acad Sci USA 82, 3000-3004 (1985)

35 Portman OW and Alexander M: Lysophosphatidylcholine concentrations and metabolism aortic intima plus inner media: effect of nutritionally induced atherosclerosis. J Lipid Res 10, $158-165$ (1969)

36 Yla-Herttuala S, Palinski W, Rosenfeld ME, Parthasarathy S, Carew TE, Butler S, Witztum JL and Steinberg D: Evidence for the presence of oxidatively modified low density lipoprotein in atherosclerotic lesions of rabbit and man. J Clin Invest 84, 1086- 1095 (1989)

37 Weinheimer $G$, Wagner $B$ and Osswald $H$ : Interaction of phorbol esters with endothelium-dependent vascular smooth muscle relaxation. Eur J Pharmacol 130, 319-322 (1986)

38 Cherry PD and Gills CN: Antagonism of acetylcholine-mediated relaxation of rabbit pulmonary arteries by phorbol myristate acetate. J Pharmacol Exp Ther 247, 542-546 (1988)

39 Rubanyi GM, Desiderio D, Luisi A, Johns A and Sybertz EJ: Phorbol dibutyrate inhibits release and action of endotheliumderived relaxing factor(s) in canine blood vessels. J Pharmacol Exp Ther 249, 858-863 (1989)

40 Morrison KJ and Pollock D: Impairment of relaxations to acetylcholine and nitric oxide by a phorbol ester in rat isolated aorta. Br J Pharmacol 101, 432-436 (1990)

41 Flavahan NA, Shimokawa $\mathbf{H}$ and Vanhoutte PM: Inhibition of endothelium-dependent relaxations by phorbol myristate acetate in canine coronary arteries: role of a pertussis toxin-sensitive G-protein. J Pharmacol Exp Ther 256, 50-55 (1991)

42 Kamata K, Chikada S, Umeda F and Kasuya Y: Effects of phorbol ester (PMA) on vasodilation induced by endotheliumdependent or endothelium-independent vasodilators in the mesenteric arterial bed. J Cardiovasc Pharmacol 26, 645-652 (1995) 